\title{
Molecular evidence of host-parasite interactions between zooplankton and Syndiniales
}

\author{
S. Zamora-Terol $(\mathbb{D} \cdot$ A. Novotny $\cdot$ M. Winder
}

Received: 10 July 2020/Accepted: 19 November 2020/Published online: 12 December 2020

(C) The Author(s) 2020

\begin{abstract}
Although parasitism is one of the most prevalent interactions in nature, studies of aquatic food webs rarely include parasites. Syndiniales (Dinophyceae, Alveolata) is a diverse parasitic group of dinoflagellates, common in all marine environments, and are described as dominant components of pelagic ecosystems. However, their temporal dynamics, prevalence, and host-specificity are poorly known. Using DNA metabarcoding to explore trophic interactions of zooplankton, we found a high proportion of Syndiniales sequence reads associated with the targeted consumers. We observed the occurrence of Syndiniales in copepods, cladocerans, appendicularians, and polychaete larvae, ranging between 11 and $36 \%$ relative read abundance, encompassing 11 main putative clades. Zooplankton-Syndiniales interactions showed variability in occurrence across the taxa, but
\end{abstract}

Handling Editor: Télesphore Sime-Ngando.

Electronic supplementary material The online version of this article (https://doi.org/10.1007/s10452-020-09816-3) contains supplementary material, which is available to authorised users.

S. Zamora-Terol $(\bowtie) \cdot$ A. Novotny $\cdot$ M. Winder Department of Ecology, Environment and Plant Science, Stockholm University, Stockholm, Sweden e-mail: szamoraterol@icloud.com; sara.zamora.terol@ni.ho

S. Zamora-Terol Institute of Marine Research, Bergen, Norway also certain host-specificity. The study suggests that the observed copepod-Syndiniales interactions can be both direct parasitic infections and the result of trophic transmission through potentially infected prey by Syndiniales. Given the quantitative importance of Syndiniales and zooplankton in marine environments, our findings emphasize that their interactions should be recognized as key players in the structure and connectivity of plankton food webs.

Keywords Syndiniales - Zooplankton $\cdot$ Hostparasite $\cdot$ Food web $\cdot$ DNA metabarcoding

\section{Introduction}

Despite the increasingly recognized relevance of parasites in food webs and biogeochemical cycling in the marine environment (Clarke et al. 2019; Lafferty et al. 2006), parasitic interactions are rarely considered in modelling or ecological investigations. Including parasites in ecological networks increases species richness and the number of food web links (Lafferty et al. 2006). Parasites can further facilitate energy transfer and promote species succession through altering interspecific competition (Valois and Poulin 2015). Marine surveys targeting the protist diversity often observe novel uncultured marine alveolate groups, which include the parasitic 
dinoflagellates Syndiniales, as the most abundant sequences (Guillou et al. 2008; Massana 2011; Cleary and Durbin 2016). Parasites of the order Syndiniales are widespread in marine environments (Clarke et al. 2019; Guillou et al. 2008; Chambouvet et al. 2011), where they can infect several types of plankton, including protozoan, such as dinoflagellates or ciliates, and metazoan (Skovgaard 2014). Syndiniales are very common in crustaceans and have been found in copepods as endoparasites (Shields 1994; Ho and Perkins 1985; Skovgaard and Saiz 2006; Coats 1999). Besides their capability to kill hosts, their ecological function remains poorly understood. Specifically, we lack a proper understanding of the potential hostspecificity, prevalence among species, and seasonality of infection, representing a major gap in our knowledge of plankton ecological interactions, and neglecting the role of parasite links in marine ecosystem functioning.

Most studies describe the diversity, occurrence, and morphology of zooplankton parasites (Skovgaard 2014; Cachon 1964; Bielecka and Boehnke 2014; Shields 1994), while few have addressed their ecological importance, including their role in population dynamics, leading to an underestimation of their relevance in the marine plankton ecosystem (Agha et al. 2016; Clarke et al. 2019; Skovgaard and Saiz 2006). Earlier studies of Syndiniales infecting zooplankton mainly include copepods in marine environments (Skovgaard et al. 2012; Skovgaard and Salomonsen 2009), but for other groups of zooplankton, like cladocerans or appendicularians, the information is almost non-existent. For cladocerans, most of the described parasites come from freshwater species and belong to other groups than Syndiniales, such as fungi, nematodes, and bacteria (Decaestecker et al. 2005). Studies of appendicularian and polychaete parasites mostly mention ciliates and apicomplexan, respectively, as main parasites with no reference to Syndiniales (Skovgaard and Saiz 2006; Lombard et al. 2010; Konovalova 2008). Few studies have described interactions between zooplankton and Syndiniales using molecular approaches (Skovgaard et al. 2005; Cleary et al. 2016), and, to our knowledge, none have explored the host-specificity and seasonality of these links.

Parasitism is one of the most common life strategies in nature (Windsor 1998; De Meeûs and Renaud 2002), including the marine ecosystem. The complexity and connectivity of trophic interactions typically increase when parasites are included in plankton networks. To highlight the potential relevance of parasites in plankton food webs, here we present a molecular exploration of interactions between Syndiniales and several zooplankton species based on $18 S$ rRNA gene sequencing. Several zooplankton organisms, including copepods, cladocerans, appendicularians, and polychaete larvae, were collected at different times of the year in the Baltic Sea and analysed using DNA metabarcoding. Our hypothesis sustains that, without discarding direct infection, zooplankton-Syndiniales interactions are partially linked to the zooplankton diet through the ingestion of parasitized prey.

\section{Material and methods}

Sampling and sorting of targeted organisms

Samples were collected in the Baltic Sea proper at the monitoring station Landsort Deep (BY31, 58 $35^{\prime} \mathrm{N}$, $18^{\circ} 14^{\prime}$ E) between June 2017 and August 2018. Water samples were collected using $10 \mathrm{~L}$ Niskin bottles from $0-30 \mathrm{~m}$ depth (obtained by mixing an equal volume of water from various Niskin bottles collected every $5 \mathrm{~m}$ ) and then filtered on board using a peristaltic pump (Masterflex L/S) onto $25 \mathrm{~mm}$ filters placed in swinnex holders (Merck/Millipore, Burlington, Massachusetts). We used 0.2 and $2 \mu \mathrm{m}$ polycarbonate, and $20 \mu \mathrm{m}$ nylon filters (when possible, 2 filter replicates were performed), and they were frozen at $-80{ }^{\circ} \mathrm{C}$ until analysis. Zooplankton samples were collected using a $90 \mu \mathrm{m}-\mathrm{WP} 2$ net $(57 \mathrm{~cm}$ diameter) with a closing system at 3 depth strata $(0-30,30-60$, and $60-100 \mathrm{~m}$ ), vertically towed, and they were gently washed and immediately preserved in $95 \%$ ethanol for later analysis in the laboratory.

Organisms sorted included: the copepods Acartia spp., Centropages hamatus, Pseudocalanus spp., and Temora longicornis; the cladocerans Evadne nordmanni, and Bosmina spp.; the appendicularian Fritillaria borealis; and the polychaete larvae Bylgides spp. For each target genus/species and sampling date, 5 replicates, each one including 5 individuals, were pooled together and used for the DNA extraction. To remove potential microorganisms attached to the body of the sorted organisms, a weak bleach solution 
(approx. 1\%) was used to rinse them, and avoid amplification of DNA adhered to appendages and body.

DNA extraction, library preparation, and sequencing

For the water samples, the DNeasy Plant Mini Kit (Qiagen, Hilden, Germany) was used to extract genomic DNA; and to extract zooplankton DNA, the QIAamp DNA Micro Kit (Qiagen) was used, previous bead beating of the samples using autoclaved $1 \mathrm{~mm}$ glass beads (Sigma-Aldrich, St. Louis, Missouri). The following PCR amplification targeted the V4 region of the $18 S$ rRNA gene, and for this, the universal primers $528 F$ (GCGGTAATTCCAGCTCCAA) and $706 R$ (AATCCRAGAATTTCACCTCT) were used (Elwood et al. 1985; Ho et al. 2017). The universality of primers was checked using the TestPrime function of the Arb-Silva website (https://www.arb-silva.de/ search/testprime/).

Illumina sequencing library preparation was performed according to best practices described by $\mathrm{Hu}$ et al. (2016). The library preparation included 2 runs of PCR amplifications. In the first one, we amplified the targeted $18 S$ rRNA gene, and in the second one, a fusion of primers, containing sample-specific barcodes (i.e. indexes) and sequencing adaptors, was used. The first PCR amplification was performed in $20 \mu \mathrm{l}$ volume, containing $10 \mu \mathrm{l}$ of KAPA HiFi HotStart ReadyMix (Roche, KAPA Biosystems, Basel, Switzerland), $1 \mu \mathrm{l}$ of each primer $(10 \mathrm{nM})$, and $2 \mu \mathrm{l}$ of template DNA. Thermal cycling conditions were: $98{ }^{\circ} \mathrm{C}$ for 2 min followed by 25 cycles of $98{ }^{\circ} \mathrm{C}$ for $20 \mathrm{~s}, 63{ }^{\circ} \mathrm{C}(16 S)$, or $54{ }^{\circ} \mathrm{C}(18 S)$ annealing for $20 \mathrm{~s}$, $72{ }^{\circ} \mathrm{C}$ for $15 \mathrm{~s}$, and a final extension step of $2 \mathrm{~min}$ at $72{ }^{\circ} \mathrm{C}$. The second PCR amplification was performed in $28 \mu \mathrm{l}$ volume, and reactions contained $14 \mu \mathrm{l}$ of KAPA HiFi HotStart ReadyMix, $1 \mu \mathrm{l}$ Handle1 (index_forward)-Adapter1 $(10 \mu \mathrm{M}), 1 \mu \mathrm{l}$ Handle2 (index_reverse)-Adapter $2(10 \mu \mathrm{M})$, and $12 \mu \mathrm{l}$ of cleaned PCR product. The thermocycling conditions were: $98{ }^{\circ} \mathrm{C}$ for 2 min followed by 10 cycles of $98{ }^{\circ} \mathrm{C}$ for $20 \mathrm{~s}, 62{ }^{\circ} \mathrm{C}$ for $30 \mathrm{~s}, 72{ }^{\circ} \mathrm{C}$ for $30 \mathrm{~s}$, and a final extension step of $2 \mathrm{~min}$ at $72{ }^{\circ} \mathrm{C}$. PCR products were purified using XP magnetic beads (Agencourt AMPure XP, Beckman Coulter, Brea, California) and quantified using a Qbit fluorometer (Qbit dsDNA HS and BRAssay Kit, Thermo Fisher, Waltham,
Massachusetts). After the second PCR, DNA concentration and quality were determined using a Qbit fluorometer (Qbit dsDNA BR Assay, Thermo Fisher) and a Bioanalyzer (Agilent 2100, Santa Clara, California). Paired-end Illumina sequencing $(2 \times 300 \mathrm{bp})$ was performed on the MiSeq platform (Illumina, SanDiego, California). A total of 165 samples were sequenced, which included 29 water samples and 136 zooplankton samples of sorted organisms.

\section{Bioinformatics and data analysis}

In an initial step, sequences were demultiplexed and excessive primer overhangs were clipped with CUTADAPT software version 1.18 (Martin 2011). We used the DADA2 pipeline for sample inference of our high-throughput amplicon data (DADA2 R package; (Callahan et al. 2016) (R Core Team 2018). We used the Naive Bayesian Classifier for rRNA taxonomic assignment (Wang et al. 2007) through the AssignTaxonomy function in DADA2. The $18 S$ rRNA gene sequences were assigned to the Protist Ribosomal Reference database (PR2) (Guillou et al. 2012). The amplicon sequence variants (ASVs) table was analysed and graphically displayed using the Phyloseq R package (McMurdie and Holmes 2013) and the GGPLOT2 package (Wickham 2009). More details of the DADA2 options used can be found in ZamoraTerol et al. (2020).

\section{Results}

We observed a high occurrence of Syndiniales reads associated with diverse zooplankton species during a survey on plankton trophic interactions in the Baltic Sea using $18 S$ rRNA gene sequencing (Fig. 1a). Syndiniales found in zooplankton represented between 11 and $36 \%$ of relative read abundance (Fig. 1a), of which Group I and IV dominated (Fig. 1b). In water samples ( $>0.2 \mu \mathrm{m} ; 0-30 \mathrm{~m}$ depth), the abundance of Syndiniales was lower than that found in zooplankton and ranged between 4 and $8 \%$ of the total detected reads (Fig. 1c). Excluding Group IV, which dominated in association with Pseudocalanus spp. (Fig. 2), Group I was the most abundant in both zooplankton and water samples (Fig. 1b, d). 
$\mathbf{a}$

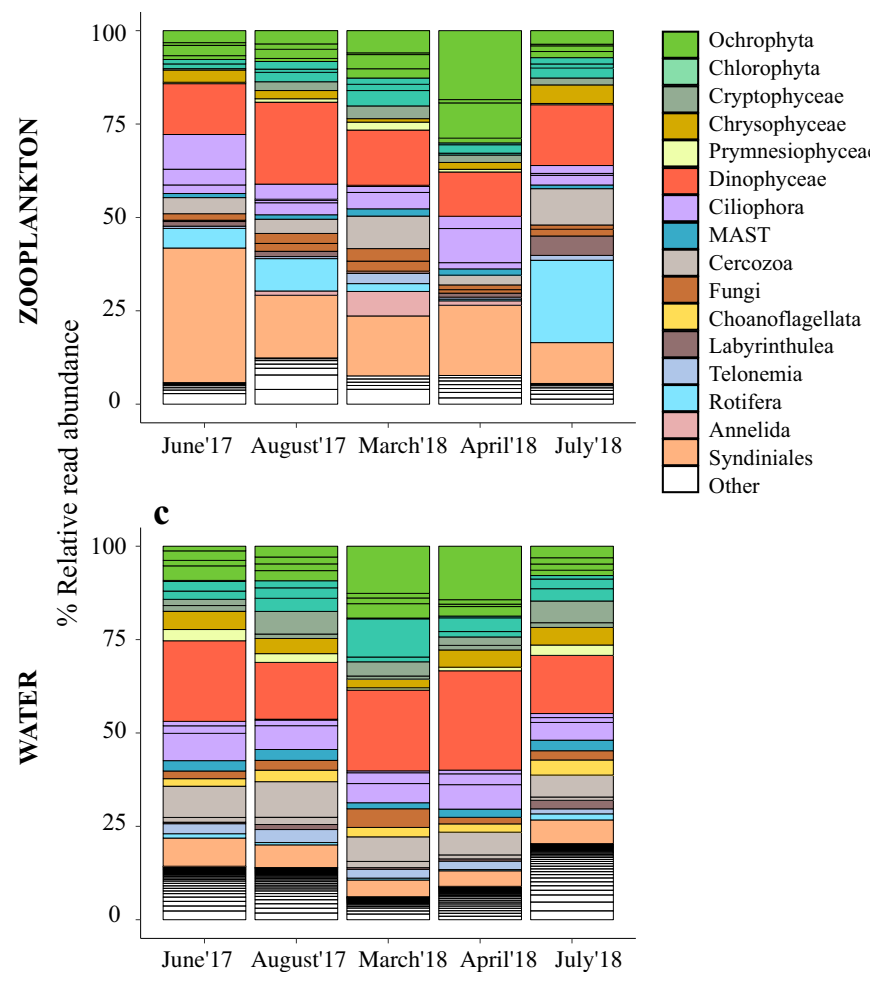

b
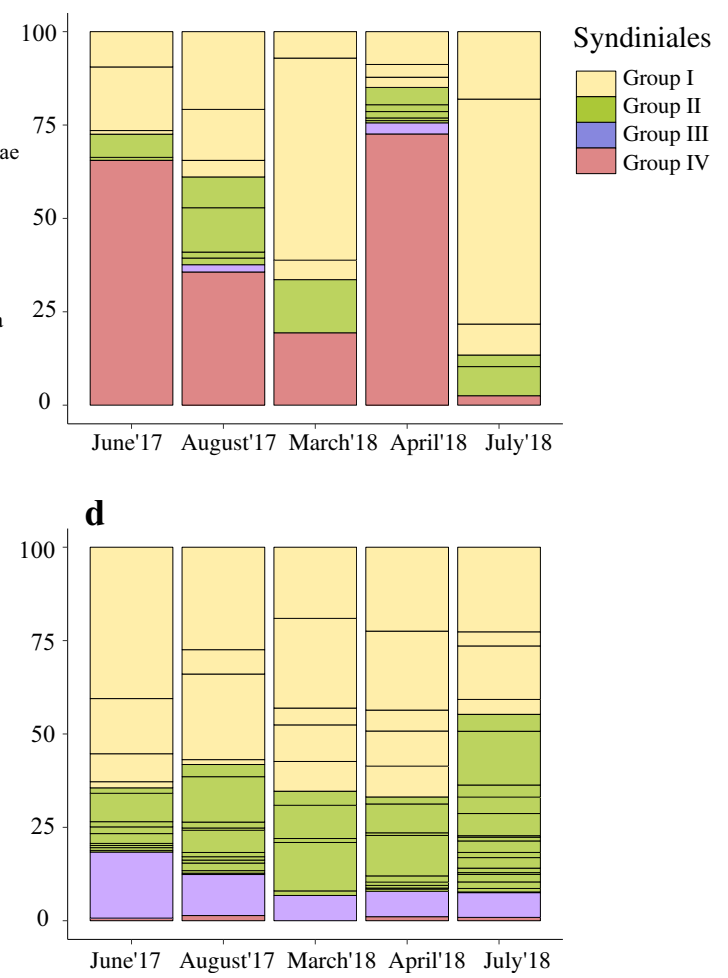

Fig. 1 Seasonal relative read abundance based on $18 S$ rRNA genes associated with selected zooplankton species including all taxa (a), including only Syndiniales (b); and water samples including all taxa (c), and only Syndiniales (d). Water samples include $18 S \mathrm{rRNA}$ gene sequences from $0-30 \mathrm{~m}$ depth

We detected parasitic dinoflagellates in all the zooplankton organisms studied, including copepods, cladocerans, appendicularians, and polychaete larvae, which were collected at different times of the year (Supplementary Table S1). Copepods showed high seasonal variability in the percentage of Syndiniales occurrence, with no general trend. Among Syndiniales associated with zooplankton, we found 11 main putative clades, which showed variability in read abundance across the targeted zooplankton taxa (Fig. 2a). Syndiniales Group I, particularly clade 1, was common in all the studied species, while the relative contribution of other clades within this group slightly differed among zooplankton hosts (Fig. 2a). Within Group I, clade 3 was the most frequent in the copepods Centropages hamatus and Temora longicornis, and the cladocerans Bosmina spp. and Evadne nordmanni; and clade 4 was present in the appendicularian Fritillaria borealis and all copepods, except and $>0.2 \mu \mathrm{m}$ size fraction (pooling data of all size fractions $0.2,2.0$, and $20 \mu \mathrm{m}$ filters). Class Arthropoda is excluded from the analysis. *Lines within the bars represent lower taxonomic levels (i.e. family) for the different groups

Acartia spp. (Fig. 2a). The polychaete larvae Bylgides sp. was exclusively associated with Group I clade 1 (Fig. 2a). Overall, Pseudocalanus was the most affected, while Temora was the least affected copepod by the occurrence of Syndiniales based on $18 S$ relative read abundance (Fig. 2b).

Within the specific groups of Syndiniales in copepod species, we found that Acartia spp. was mostly linked to Group II clades, Centropages hamatus and Temora longicornis to clades of Group I, and Pseudocalanus spp. to Group IV-Hematodinium (Fig. 2c). In particular, Acartia showed a high relative read abundance of clade 4 within Group II (Fig. 2c), and in general, this copepod showed the highest proportion of this particular clade (Fig. 2a). Temora and Centropages shared most of the clades in similar proportions, although Group III was only present in Temora (Fig. 2c). Pseudocalanus was the copepod most highly associated with the Group IV-Hematodinium, 
a

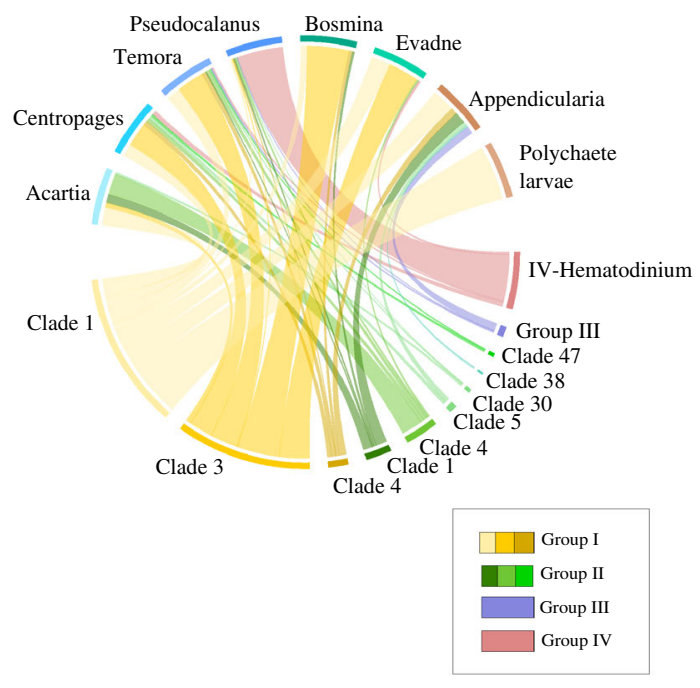

b
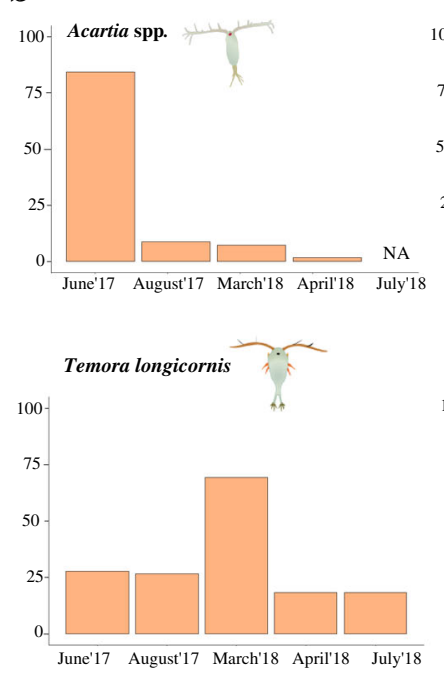
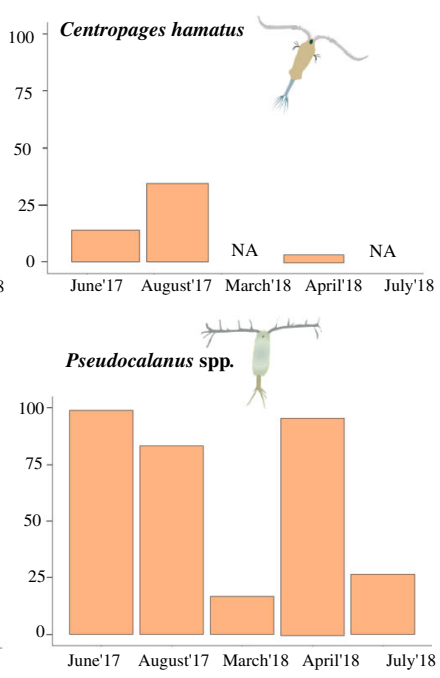

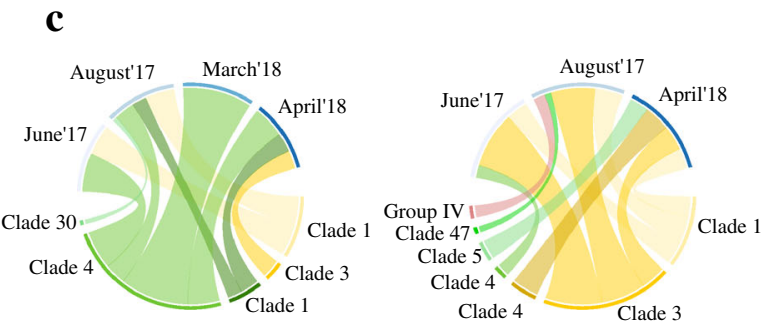

Acartia spp.

Centropages hamatus
Fig. 2 Zooplankton-Syndiniales interactions. (a) Taxon-specific zooplankton-Syndiniales interactions averaged over the sampling period represented in circos plots. Zooplankton taxa are shown at the top and the associated parasitic Syndiniales groups on the bottom of the plot. (b) Percentage of Syndiniales contribution to total $18 S$ rRNA gene reads associated with dominant copepod species over the season. (c) Host-specific interactions of Syndiniales, with dominant copepod species over the season shown as circa plots. Months are shown at the top,

except in July 2018, when the presence of Group II was higher compared to Syndiniales in other months (Fig. 2b and c).

\section{Discussion}

Our study shows that a molecular approach allows the detection of Syndiniales interactions with zooplankton organisms, providing insights about their importance as potentially key players in the structure and connectivity of plankton food webs. Our results confirm previous observations of the high occurrence

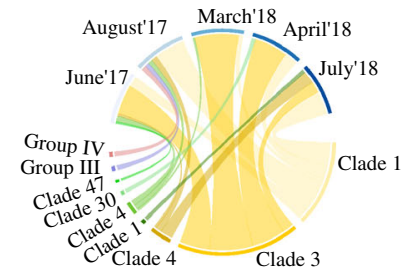

Temora longicornis

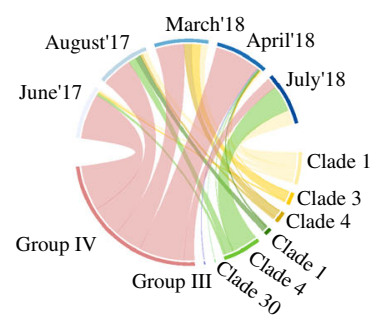

Pseudocalanus spp. and the associated clades of Syndiniales at the bottom of the plot. *Circos plots: The width of the connection ribbons represents the relative abundance of a particular clade of Syndiniales associated with zooplankton organisms (a) or month (c), and the width of each clade segment is proportional to the relative abundance of each clade considering all Syndiniales. Arthropoda sequences are excluded in the plots. Syndiniales clades are colour coded by Syndiniales groups, and common for all plots

of Syndiniales in the ocean and within the zooplankton community with certain host-specificity of some clades (Coats and Park 2002; Guillou et al. 2008; Clarke et al. 2019). We suggest that the zooplanktonSyndiniales interactions observed can be both direct parasitic infections and the result of an indirect uptake through consumption of infected prey organisms.

The percentage of Syndiniales reads found in the water samples is in accordance with other Baltic Sea reports (Majaneva et al. 2012), as well as in other ocean regions (Clarke et al. 2019). The dominance of Group I and IV that we found in this study is also described in previous investigations (Sassenhagen 
et al. 2020; Clarke et al. 2019; Lima-Mendez et al. 2015). Analysing size fractions of water samples (data not shown), allowed us to affirm that not only freeliving dinospores $(3-10 \mu \mathrm{m})$ (Chambouvet et al. 2011) were present in the water, but also infecting stages of Syndiniales associated with larger cells ( $>20 \mu \mathrm{m}$ ). The predominance of Groups I and IV associated with zooplankton observed in our study was previously described for the same taxa (Skovgaard 2014). Syndiniales Group IV are well-known parasites of crustaceans, including copepods (Shields 1994; Skovgaard et al. 2005), but little is known about Group $\mathrm{I}$, which is considered as one of the enigmatic groups within marine alveolates (Harada et al. 2007; Bråte et al. 2012). Interestingly, from all the groups detected, we found Group I common in all zooplankton organisms studied here, particularly clade 1 (Fig. 2a), being also the most frequent in water samples in terms of relative read abundance (Fig. 1d).

The wide spectrum of infection suggested for Syndiniales Group I might indicate low host-specificity and explain why we found this group associated with all zooplankton (Sassenhagen et al. 2020; Guillou et al. 2008). An alternative explanation for the presence of Group I in all zooplankton groups is based on previous investigations where Syndiniales Group I was found associated with cercozoans (Dolven et al. 2007; Clarke et al. 2019; Sassenhagen et al. 2020), taxa that we found often abundant both in the water and associated with all zooplankton (Fig. 1a, c). This suggests that the wide spectrum of infection of Group I is potentially linked to the ingestion of cercozoan by all zooplankton consumers. However, it has recently been suggested that Syndiniales Group I might infect diatoms, and Syndiniales associated with Cercozoa might be the result of predation on infected diatoms (Sassenhagen et al. 2020), emphasizing the high complexity of the biotic interactions that we found in plankton communities. Our observations might also support this hypothesis because diatoms were shared as prey by all the zooplankton consumers (Zamora-Terol et al. 2020), in particular Thalassiosira, one of the genera suggested by Sassenhagen et al. 2020 to be infected by Syndiniales Group I. However, if this interaction between zooplankton and Syndiniales Group I is the result of a direct (i.e. ingestion of infected diatoms) or indirect (i.e. ingestion of cercozoan that has predated on infected diatoms) trophic link needs further support. There are no literature reports on infection of diatoms by Syndiniales, thus to validate this hypothesis we need further investigations and the use of techniques, such as fluorescence in situ hybridization (FISH), that can provide visual evidence of these potential interactions.

Based on molecular approaches, putative symbionts of copepods are observed abundantly in marine water samples at a global scale (Lima-Mendez et al. 2015; Vargas et al. 2015), as well as within copepod guts (Lima-Mendez et al. 2015; Ray et al. 2016). Earlier studies have reported seasonality in infection prevalence of zooplankton (Duffy et al. 2005) associated with the sporulation of the parasite, which is likely affected by decreasing temperatures (Shields 1994). However, we found no clear seasonal pattern of Syndiniales occurrence in copepods nor the water samples (Fig. 2b) and temperature in connection with the sampling dates (Supplementary Table S1). In general, we found that Acartia spp. was mainly linked to read sequences of Syndiniales Group II (clade 4), Temora longicornis and Centropages hamatus to Group I, and Pseudocalanus spp. to Group IVHematodinium (Fig. 2c). These copepod-Syndiniales specific patterns are in line with the reported natural diet overlap and difference between these copepods (Zamora-Terol et al. 2020). For example, C. hamatus and $T$. longicornis shared the predominance of Group I clade 3 Syndiniales (Fig. 2c), and they shared particular species of diatoms and dinoflagellates as predominant prey ingested (Fig. 3). These prey were also abundant in water samples (Fig. 1c), in which we also found a predominance of Group I (Fig. 1d), suggesting that parasites are ingested with the prey. Unfortunately, information on the ecology of Syndiniales Group I clade 3 is scarce to confirm this link.

We found other potential trophic connections with the groups of Syndiniales. Syndiniales Group II, which is closely related to Amoebophrya, was mainly associated with Acartia spp. (Fig. 2c). Amoebophrya is the most studied parasite genus in Syndiniales Group II and can infect, among other taxa, dinoflagellates, cnidarians, and ciliates (Cachon 1964; LimaMendez et al. 2015; Jephcott et al. 2016). We found all those taxa in the gut samples of Acartia spp. (Fig. 3), suggesting that the observed interaction could be the result of the ingestion of infected prey. We also found the presence of Group II in the appendicularian Fritillaria borealis and the copepod Centropages hamatus in April (Fig. 2), which could indicate that 
Fig. 3 Seasonal relative read abundance of potential prey associated with copepod samples based on 18S rRNA gene sequencing at station BY31 in the Baltic Sea. Class Arthropoda is excluded from the analysis

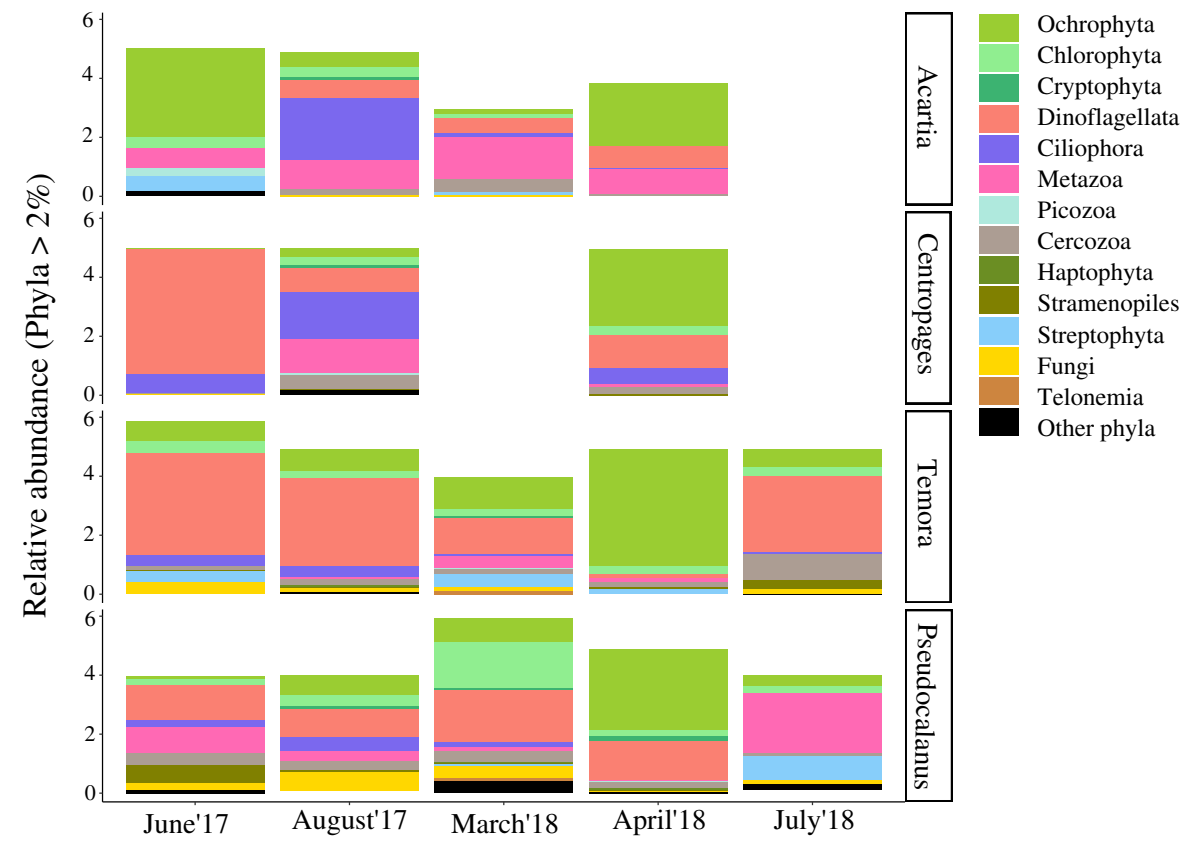

they shared a particular prey in that period of the year. We suggest that the ciliate Cyclotrichium spp., which we found as prey in both $F$. borealis and $C$. hamatus but not in other copepods (data not shown) might explain their interaction with Syndiniales Group II (Fig. 2). Although copepods and appendicularians have different feeding strategies, they can feed on the same prey by performing different feeding behaviours. While certain copepods perform selective feeding, such as Acartia and Centropages (Meunier et al. 2016; Wiadnyana and Rassoulzadegan 1989), filter feeders, such as appendicularians and cladocerans are capable of rejecting prey (Lombard et al. 2011; Katechakis and Stibor 2004). This would explain why cladocerans and appendicularians do not share the same groups of Syndiniales despite having the same feeding strategy, and why appendicularians, Acartia, and Centropages do share the presence of Group II (Fig. 2).

The copepod Pseudocalanus showed the highest relative abundance of parasitic reads among the observed zooplankton taxa and was almost exclusively associated with Group IV-Hematodinium (Fig. 2c). Pseudocalanus spp. feed, among other items, on detritus and particulate organic matter (Poulet 1973). This feeding behaviour might explain the potential ingestion of free-living dinospores, which can survive several days without a host (Coats and Park 2002) and can adhere to detritus (Drebes 1981). However, and due to the high presence of parasites, a direct infection with parasites of Group IV-Hematodinium is also likely. Syndinids are well known to infect copepods, and Pseudocalanus have been found infected with syndinids such as Syndinium, which belongs to the Group IV-Hematodinium (Kimmerer and McKinnon 1990; Ianora et al. 1990). Our observations are in line with a previous dietary study (Cleary et al. 2016) and molecular evidence of interactions between the syndinid Hematodinium and calanoid copepods (Henry 2016), although the nature of these interactions is unknown.

Our data suggest predation on parasites, through infected prey, as a potential uptake pathway for certain copepods, and thus, the natural diet of copepods might play a role in the host preference of Syndiniales (Fig. 4). This is in contrast with the assumed opportunistic or generalist behaviour of these parasites (Guillou et al. 2008). Consequently, copepods that share prey may also be linked to the same groups of Syndiniales, likely discarding a direct parasitic infection, except for Pseudocalanus spp. and Syndiniales Group IV. These hypotheses need further support since the molecular work on syndinids is not extensive, but in any case, they highlight the potential complexity underlying the observed association between Syndiniales and marine zooplankton. Also, the prevalence of Syndiniales observed among 


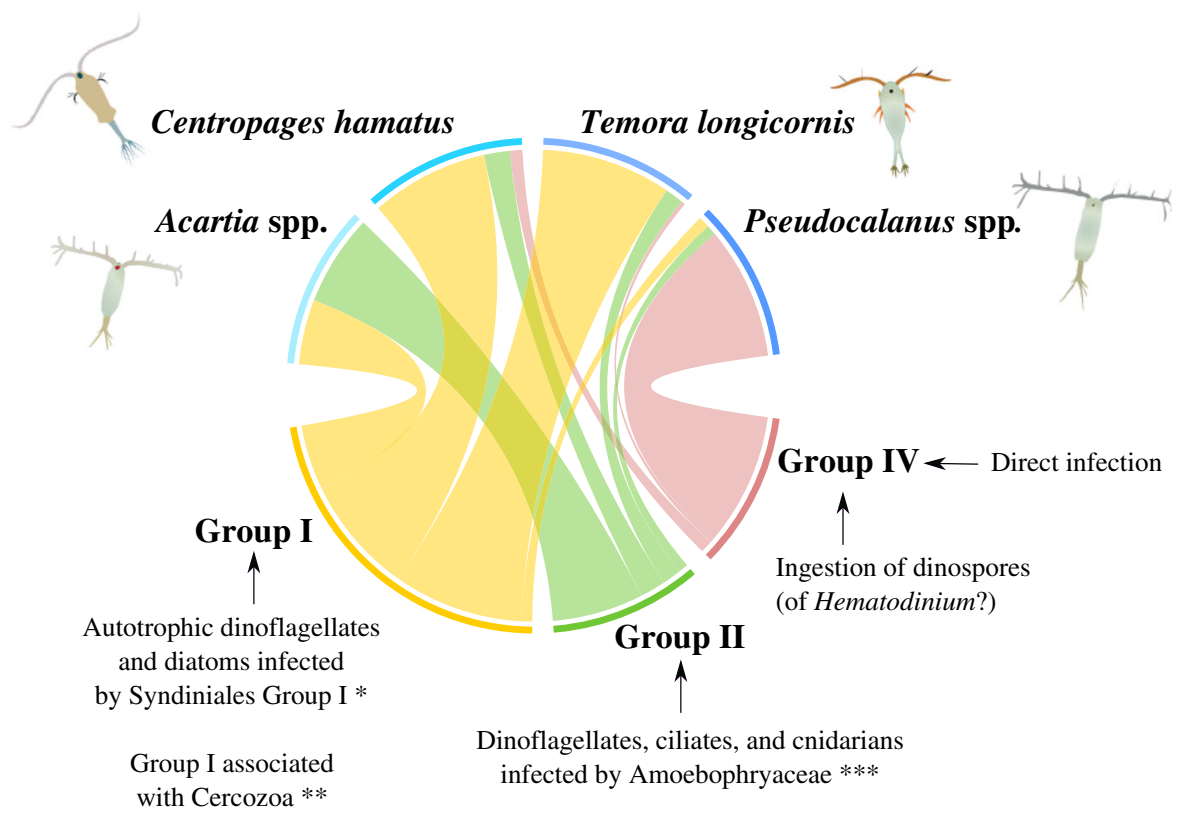

Fig. 4 Schematic representation of potential host-parasite interactions between copepods and Syndiniales based on results from this study and literature information. *Lima-Méndez et al.

copepod species in this study indicates the importance of parasites in plankton food webs.

The application of molecular techniques, as conducted in this study (i.e. targeting specific taxa), is emerging as a promising tool to gain insight into ecological interactions, including parasitic, since it allows unveiling interactions that can only be assumed from indirect approaches, such as correlating taxa abundances over time or space (Lima-Mendez et al. 2015). Uncovering the mechanisms that underlie these relationships, however, requires additional techniques (e.g. microscopy, in situ hybridization, histology) to validate molecular data and visualize interactions for a better comprehension of marine processes (Sebastián and Gasol 2019). Given the quantitative importance of Syndiniales and zooplankton in marine environments, their interactions should be recognized as keystone links in the prediction of nutrient and energy fluxes in the ocean and included in food web studies for a holistic understanding of the marine ecosystem function.

Acknowledgements We thank the Marine Pelagic Ecology Laboratory at Stockholm University for providing ship time and a working platform for sampling. We would also like to acknowledge support from Science for Life Laboratory and the
2015 and Sassenhagen et al. 2020; **Clarke et al. 2019; ***Cachon 1964 and Sassenhagen et al. 2020

National Genomics Infrastructure for assisting in massive parallel sequencing, and to the Swedish National Infrastructure for Computing (SNIC), which provided resources for computation through Uppsala Multidisciplinary Center for Advanced Computational Science (UPPMAX). Thanks Clara Ruiz-González for your valuable suggestions. Finally, we thank the 3 anonymous reviewers for their constructive comments and suggestions.

Author contributions All authors contributed to the study conception and design of the research. S.Z.T. and A.N. coordinated the fieldwork, collected samples, and performed assay optimization and laboratory processing of samples. S.Z.T. analysed the data, produced the graphics, and wrote the manuscript with the support of M.W and A.N.

Funding Open Access funding provided by Institute Of Marine Research. This study was funded by the Swedish Research Council Vetenskapsrådet project number 2016-04685.

Data availability Sample metadata and amplicon sequence variants table (ASV) with read count per sample, and taxonomic assignment are available from the Zenodo repository with https://doi.org/10.5281/zenodo.3731296 (https://doi.org/10. 5281/zenodo.3731296). DNA sequences and associated metadata have been deposited in the European Nucleotide Archive (ENA) under accession number PRJEB39191 (https://www.ebi. ac.uk/ena/browser/view/PRJEB39191). 


\section{Compliance with ethical standards}

Conflict of interest The authors declare that they have no competing financial interests or personal relationships that could have appeared to influence the work reported in this paper.

Open Access This article is licensed under a Creative Commons Attribution 4.0 International License, which permits use, sharing, adaptation, distribution and reproduction in any medium or format, as long as you give appropriate credit to the original author(s) and the source, provide a link to the Creative Commons licence, and indicate if changes were made. The images or other third party material in this article are included in the article's Creative Commons licence, unless indicated otherwise in a credit line to the material. If material is not included in the article's Creative Commons licence and your intended use is not permitted by statutory regulation or exceeds the permitted use, you will need to obtain permission directly from the copyright holder. To view a copy of this licence, visit http://creativecommons.org/licenses/by/4.0/.

\section{References}

Agha R, Saebelfeld M, Manthey C, Rohrlack T, Wolinska J (2016) Chytrid parasitism facilitates trophic transfer between bloom-forming cyanobacteria and zooplankton (Daphnia). Sci rep 6:35039

Bielecka L, Boehnke R (2014) Epibionts and parasites on crustaceans (Copepoda, Cladocera, Cirripedia larvae) inhabiting the Gulf of Gdańsk (Baltic Sea) in very large numbers. Oceanol 56:629-638

Bråte J, Krabberød AK, Dolven JK, Ose RF, Kristensen T, Bjørklund KR, Shalchian-Tabrizi K (2012) Radiolaria associated with large diversity of marine alveolates. Protist 163:767-777

Cachon J (1964) Contribution à l'étude des péridiniens parasites. Cytologie, cycles évolutifs. Ann. Sci. nat. zoologie, Paris, 6, 1-158

Callahan BJ, McMurdie PJ, Rosen MJ, Han AW, Johnson AJA, Holmes SP (2016) DADA2: high-resolution sample inference from Illumina amplicon data. Nat Methods 13:581

Chambouvet A, Alves-de-Souza C, Cueff V, Marie D, Karpov S, Guillou L (2011) Interplay between the parasite Amoebophrya sp. (Alveolata) and the cyst formation of the red tide dinoflagellate Scrippsiella trochoidea. Protist 162:637-649

Clarke LJ, Bestley S, Bissett A, Deagle BE (2019) A globally distributed Syndiniales parasite dominates the Southern Ocean micro-eukaryote community near the sea-ice edge. The ISME j 13:734-737

Cleary AC, Durbin EG (2016) Unexpected prevalence of parasite 18S rDNA sequences in winter among Antarctic marine protists. J Plankton Res 38:401-417

Cleary AC, Durbin EG, Rynearson TA, Bailey J (2016) Feeding by Pseudocalanus copepods in the Bering Sea: trophic linkages and a potential mechanism of niche partitioning. Deep-Sea Res II 134:181-189
Coats DW (1999) Parasitic life styles of marine dinoflagellates 1. J Eukaryot Microbiol 46:402-409

Coats DW, Park MG (2002) Parasitism of photosynthetic dinoflagellates by three strains of Amoebophrya (dinophyta): parasite survival, infectivity, generation time, and host specificity. J Phycol 38:520-528

De Meeûs T, Renaud F (2002) Parasites within the new phylogeny of eukaryotes. Trends in parasitol 18:247-251

Decaestecker E, Declerck S, De Meester L, Ebert D (2005) Ecological implications of parasites in natural Daphnia populations. Oecol 144:382-390

Dolven JK, Lindqvist C, Albert VA, Bjørklund KR, Yuasa T, Takahashi O, Mayama S (2007) Molecular diversity of alveolates associated with neritic North Atlantic radiolarians. Protist 158:65-76

Drebes G (1981) Possible resting spores of Dissodinium pseudolunula (Dinophyta) and their relation to other taxa. Brit Phycol J 16:207-215

Duffy MA, Hall SR, Tessier AJ, Huebner M (2005) Selective predators and their parasitized prey: are epidemics in zooplankton under top-down control? Limnol Oceanogr 50:412-420

Elwood H, Olsen GJ, Sogin M (1985) The small-subunit ribosomal RNA gene sequences from the hypotrichous ciliates Oxytricha nova and Stylonychia pustulata. Mol Biol Evol 2:399-410

Guillou L, Bachar D, Audic S, Bass D, Berney C, Bittner L, Boutte C, Burgaud G, de Vargas C, Decelle J (2012) The protist ribosomal reference database (PR2): a catalog of unicellular eukaryote small sub-unit rRNA sequences with curated taxonomy. Nucleic Acids Res 41:D597-D604

Guillou L, Viprey M, Chambouvet A, Welsh R, Kirkham A, Massana R, Scanlan DJ, Worden AZ (2008) Widespread occurrence and genetic diversity of marine parasitoids belonging to Syndiniales (Alveolata). Environ Microbiol 10:3349-3365

Harada A, Ohtsuka S, Horiguchi T (2007) Species of the parasitic genus Duboscquella are members of the enigmatic Marine Alveolate Group I. Protist 158:337-347

Henry N, (2016) Molecular ecology of eukaryotic symbioses in the planktonic ecosystems of the oceanic photic zone. Dissertation. Université Pierre et Marie Curie-Paris VI

Ho J-s, Perkins PS (1985) Symbionts of marine copepoda: an overview. Bull Mar Sci 37:586-598

Ho TW, Hwang J-S, Cheung MK, Kwan HS, Wong CK (2017) DNA-based study of the diet of the marine calanoid copepod Calanus sinicus. J Exp Mar Biol Ecol 494:1-9

$\mathrm{Hu}$ YO, Karlson B, Charvet S, Andersson AF (2016) Diversity of pico-to mesoplankton along the $2000 \mathrm{~km}$ salinity gradient of the Baltic Sea. Front Microbiol 7:679

Ianora A, di Carlo BS, Mazzocchi M, Mascellaro P (1990) Histomorphological changes in the reproductive condition of parasitized marine planktonic copepods. J Plankton Res 12:249-258

Jephcott TG, Alves-de-Souza C, Gleason FH, Van Ogtrop FF, Sime Ngando T, Karpov SA, Guillou L (2016) Ecological impacts of parasitic chytrids syndiniales and perkinsids on populations of marine photosynthetic dinoflagellates. Fungal Ecol 19:47-58 
Katechakis A, Stibor H (2004) Feeding selectivities of the marine cladocerans penilia avirostris, Podon intermedius and Evadne nordmanni. Mar Biol 145:529-539

Kimmerer W, McKinnon A (1990) High mortality in a copepod population caused by a parasitic dinoflagellate. Mar Biol 107:449-452

Konovalova G (2008) Parasitic dinoflagellates and ellobiopsids (Ellobiopsidae) of the coastal waters of the Sea of Japan. Russ j marine biol 34:28-37

Lafferty KD, Dobson AP, Kuris AM (2006) Parasites dominate food web links. Proc Natl Acad Sci 103:11211-11216

Lima-Mendez G, Faust K, Henry N, Decelle J, Colin S, Carcillo F, Chaffron S, Ignacio-Espinosa JC, Roux S, Vincent F, Bittner L, Darzi Y, Wang J, Audic S, Berline L, Bontempi G, Cabello AM, Coppola L, Cornejo-Castillo FM, d'Ovidio F, De Meester L, Ferrera I, Garet-Delmas M-J, Guidi L, Lara E, Pesant S, Royo-Llonch M, Salazar G, Sánchez P, Sebastian M, Souffreau C, Dimier C, Picheral M, Searson S, Kandels-Lewis S, Gorsky G, Not F, Ogata H, Speich S, Stemmann L, Weissenbach J, Wincker P, Acinas SG, Sunagawa S, Bork P, Sullivan MB, Karsenti E, Bowler C, de Vargas C, Raes J (2015) Determinants of community structure in the global plankton interactome. Science 348(6237):1262073. https://doi.org/10.1126/science. 1262073

Lombard F, Eloire D, Gobet A, Stemmann L, Dolan JR, Sciandra A, Gorsky G (2010) Experimental and modeling evidence of appendicularian-ciliate interactions. Limnol Oceanogr 55:77-90

Lombard F, Selander E, Kiørboe T (2011) Active prey rejection in the filter-feeding appendicularian Oikopleura dioica. Limnol Oceanogr 56:1504-1512

Majaneva M, Rintala J-M, Piisilä M, Fewer DP, Blomster J (2012) Comparison of wintertime eukaryotic community from sea ice and open water in the Baltic Sea, based on sequencing of the 18S rRNA gene. Pol Biol 35:875-889

Martin M (2011) Cutadapt removes adapter sequences from high-throughput sequencing reads. EMBnet j 17:10-12

Massana R (2011) Eukaryotic picoplankton in surface oceans. Annu Rev Microbiol 65:91-110

McMurdie PJ, Holmes S (2013) phyloseq: an R package for reproducible interactive analysis and graphics of microbiome census data. PLoS ONE 8:e61217

Meunier CL, Boersma M, Wiltshire KH, Malzahn AM (2016) Zooplankton eat what they need: copepod selective feeding and potential consequences for marine systems. Oikos 125:50-58

Poulet S (1973) Grazing of Pseudocalanus minutus on naturally occurring particulate matter. Limnol Oceanogr 18:564-573

R Core Team (2018) R: a language and environment for statistical computing (Version 3.5.2). R Foundation for Statistical Computing, Vienna, Austria

Ray JL, Althammer J, Skaar KS, Simonelli P, Larsen A, Stoecker D, Sazhin A, Ijaz UZ, Quince C, Nejstgaard JC (2016) Metabarcoding and metabolome analyses of copepod grazing reveal feeding preference and linkage to metabolite classes in dynamic microbial plankton communities. Mol Ecol 25:5585-5602

Sassenhagen I, Irion S, Jardillier L, Moreira D, Christaki U (2020) Protist interactions and community structure during early autumn in the Kerguelen region (Southern Ocean). Protist 171:125709

Sebastián M, Gasol JM (2019) Visualization is crucial for understanding microbial processes in the ocean. Philos Trans Royal Soc B 374:20190083

Shields JD (1994) The parasitic dinoflagellates of marine crustaceans. Annu Rev Fish Dis 4:241-271

Skovgaard A, (2014) Dirty tricks in the plankton: diversity and role of marine parasitic protists. Acta Protozool 53(1)

Skovgaard A, Karpov SA, Guillou L (2012) The parasitic dinoflagellates Blastodinium spp. inhabiting the gut of marine, planktonic copepods: morphology, ecology, and unrecognized species diversity. Front Microbiol 3:305

Skovgaard A, Massana R, Balague V, Saiz E (2005) Phylogenetic position of the copepod-infesting parasite Syndinium turbo (Dinoflagellata, Syndinea). Protist 156:413-423

Skovgaard A, Saiz E (2006) Seasonal occurrence and role of protistan parasites in coastal marine zooplankton. Mar Ecol Prog Ser 327:37-49. https://doi.org/10.3354/meps327037

Skovgaard A, Salomonsen XM (2009) Blastodinium galatheanum sp. nov. (Dinophyceae) a parasite of the planktonic copepod Acartia negligens (Crustacea, Calanoida) in the central Atlantic Ocean. Eur J Phycol 44:425-438. https:// doi.org/10.1080/09670260902878743

Valois AE, Poulin R (2015) Global drivers of parasitism in freshwater plankton communities. Limnol Oceanogr 60:1707-1718

Vargas C, Audic S, Henry N, Decelle J, Mahé F, Logares R, Lara E, Berney C, Le Bescot N, Probert I, Carmichael M, Poulain J, Romac S, Colin S, Aury J-M, Bittner L, Chaffron S, Dunthorn M, Engelen S, Flegontova O, Guidi L, Horák A, Jaillon O, Lima-Mendez G, Lukeš J, Malviya S, Morard R, Mulot M, Scalco E, Siano R, Vincent F, Zingone A, Dimier C, Picheral M, Searson S, Kandels-Lewis S, Acinas SG, Bork P, Bowler C, Gorsky G, Grimsley N, Hingamp P, Iudicone D, Not F, Ogata H, Pesant S, Raes J, Sieracki ME, Speich S, Stemmann L, Sunagawa S, Weissenbach J, Wincker P, Karsenti E (2015) Eukaryotic plankton diversity in the sunlit ocean. Sci. https://doi.org/10.1126/ science. 1261605

Wang Q, Garrity GM, Tiedje JM, Cole JR (2007) Naïve bayesian classifier for rapid assignment of rRNA sequences into the new bacterial taxonomy. Appl Environ Microbiol 73(16):5261-5267

Wiadnyana NN, Rassoulzadegan F (1989) Selective feeding of Acartia clausi and Centropages typicus on microzooplankton. Mar Ecol Prog Ser 53:37-45

Wickham H (2009) Elegant graphics for data analysis (ggplot2). Springer-Verlag, New York, NY

Windsor DA (1998) Controversies in parasitology, Most of the species on Earth are parasites. Int J Parasitol 28:1939-1941

Zamora-Terol S, Novotny A, Winder M (2020) Reconstructing marine plankton food web interactions using DNA metabarcoding. Mol Ecol 29:3380-3395. https://doi.org/ 10.1111/mec. 15555

Publisher's Note Springer Nature remains neutral with regard to jurisdictional claims in published maps and institutional affiliations. 